\title{
Detection of Organochlorine Pesticides in Contaminated Marine Environments via Cyclodextrin-Promoted Fluorescence Modulation
}

\author{
Dana J. DiScenza, Julie Lynch, Jasmine Miller, Molly Verderame, and Mindy Levine*(*) \\ Department of Chemistry, University of Rhode Island, 140 Flagg Road, Kingston, Rhode Island 02881, United States
}

Supporting Information

ABSTRACT: The development of practical and robust detection methods for pesticides is an important research objective owing to the known toxicity, carcinogenicity, and environmental persistence of these compounds. Pesticides have been found in bodies of water that are located near areas where pesticides are commonly used and easily spread to beaches, lakes, and rivers; affect the species living in those waterways; and harm humans who come into contact with or eat fish from such water. Reported herein is the rapid, sensitive, and selective detection of four organochlorine pesticides in a variety of water sources across the state of Rhode Island using cyclodextrin-promoted fluorescence
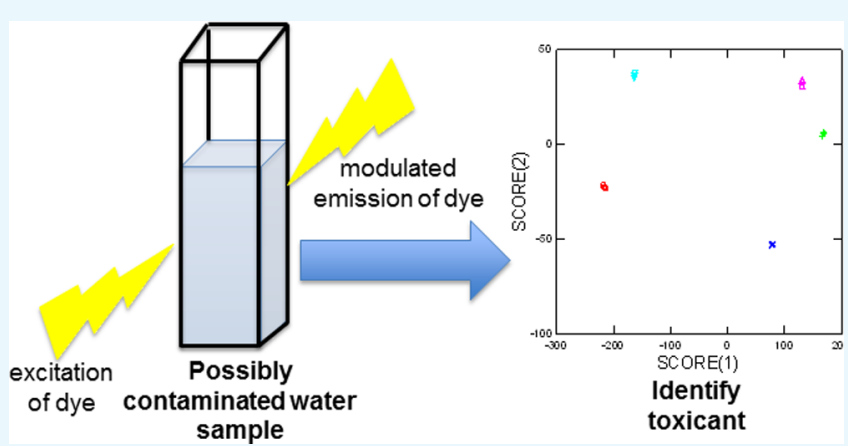

detection. This method relies on the ability of cyclodextrin to promote analyte-specific fluorescence modulation of a high quantum yield fluorophore when a pesticide is in close proximity, combined with subsequent array-based statistical analyses of the measurable changes in the emission signals. This system operates with high sensitivity (low micromolar detection limits), selectivity (100\% differentiation between structurally similar analytes), and general applicability (for different water samples with varying salinity and $\mathrm{pH}$ as well as for different water temperatures).

\section{INTRODUCTION}

Pesticides are a ubiquitous class of organic pollutants known for their environmental persistence ${ }^{1-3}$ carcinogenicity; ${ }^{4,5}$ and toxicity to humans, ${ }^{6}$ animals, ${ }^{7}$ and plants. ${ }^{8}$ These compounds are used widely by farmers worldwide to control insects, fungi, and other pests ${ }^{9,10}$ and to maximize crop yields and food production. $^{11,12}$ Once released into the environment, pesticides spread widely, persisting in water, ${ }^{13}$ air, ${ }^{14}$ soil, ${ }^{15}$ and sediment. ${ }^{16}$ Most of these pesticides are resistant to hydrolysis and degrade slowly under standard environmental conditions; ${ }^{17-19}$ as a result, pesticides both bioaccumulate and biomagnify in the food chain ${ }^{20}$ and have exacerbated negative effects to humans and animals. ${ }^{21,22}$

The ability to detect pesticides is an important research objective with significant applications in the food and agricultural industries, ${ }^{23,24}$ public health policies, ${ }^{25,26}$ and a variety of other scientific subdisciplines. ${ }^{27}$ Currently used methods for such detection rely heavily on mass spectrometrybased techniques, ${ }^{28-30}$ which are time-consuming, expensive, and often require additional preparation procedures prior to analysis. Newer detection methods using techniques such as Raman spectroscopy ${ }^{31,32}$ or electrochemical assays ${ }^{33}$ have recently been developed and demonstrated extremely high sensitivity; however, each of these techniques also requires significant time and resources, which can limit the ability to conduct high-throughput assays of large populations to monitor widespread pesticide exposure.
Previous work in our laboratory has focused on the use of cyclodextrin-promoted fluorescence energy transfer for the rapid, sensitive, and selective detection of aromatic toxicants. ${ }^{34-37}$ This system relies on the ability of cyclodextrin to promote proximity-induced energy transfer from an aromatic toxicant energy donor to a high quantum yield fluorophore acceptor, leading to a bright, turn-on fluorescence signal that is unique to each cyclodextrin-analyte-fluorophore combination. We have shown that such detection operates successfully in purified buffer solutions, ${ }^{38}$ human urine, ${ }^{39}$ and human breast milk; ${ }^{40}$ that it can form a part of oil spill remediation procedures using the cyclodextrin-promoted toxicant extraction followed by fluorescence detection; ${ }^{41-44}$ and that it can be used for the detection of both polar and nonpolar photophysically active toxicants. $^{45}$

In cases where the target analyte is not photophysically active and cannot participate in energy transfer, highly analyte-specific fluorescence modulation can still occur, in which the cyclodextrin promotes proximity-induced changes in the fluorophore emission signal when the target analyte is in close proximity. This fluorescence modulation-based system has been used successfully in the detection of fuel components including benzene and alkylated benzene derivatives in contaminated water samples, ${ }^{46}$ as well as in the detection of nonaromatic

Received: July 13, 2017

Accepted: November 3, 2017

Published: December 1, 2017 
alcohols $^{47}$ and organochlorine pesticides ${ }^{48}$ in purified buffer systems.

One environment that is particularly important is water because toxicants found in aqueous environments will affect people who drink the water, organisms that live in water (i.e., seafood), and people who consume such organisms. Although our previously reported cyclodextrin-based systems provided accurate pesticide detection in purified buffer systems, there are substantial differences between such purified buffer solutions and real-world aqueous environments that complicate the development and optimization of toxicant detection methods. In particular, real-world aqueous environments contain a plethora of living species (both plant and animal), can have high salinity (in saltwater systems) and a broad variety of $\mathrm{pHs,}$ and can be found at a variety of temperatures (depending on geographic location and season).

Reported herein is the rapid, sensitive, and selective detection of four organochlorine pesticides in water sources across the state of Rhode Island using cyclodextrin-promoted fluorescence modulation. We demonstrate that this system operates with high sensitivity (low micromolar detection limits), selectivity (100\% differentiation between compounds), and general applicability (for different water samples with varying salinity and $\mathrm{pH}$ as well as for different temperatures of these water samples).

\section{EXPERIMENTAL SECTION}

All organochlorine pesticides and control analytes (compounds 1-5, Figure 1) were purchased from Sigma-Aldrich chemical

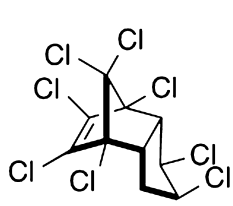

cis-chlordane

1

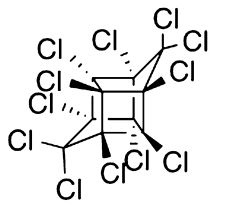

mirex

4<smiles>ClC1=C(Cl)C2(Cl)C(Cl)C=CC(C2Cl)C1(Cl)Cl</smiles>

heptachlor

2<smiles>C1CCOC1</smiles>

tetrahydrofuran

5<smiles>ClC1[C@H](Cl)[C@H](Cl)[C@@H](Cl)[C@H](Cl)[C@H]1Cl</smiles>

lindane

3<smiles>CC1=CC(C)=NC1C(CO)C(CO)c1c(C)cc(C)n1P(F)F</smiles>

BODIPY

6
Figure 1. Structures of analytes 1-5 and fluorophore 6.

company and used as received, unless otherwise noted. Fluorophore $\mathbf{6}$ was synthesized following literature-reported procedures. ${ }^{49}{ }^{1} \mathrm{H}$ NMR spectra were recorded using a Bruker $300 \mathrm{MHz}$ spectrometer. UV-visible spectra were recorded using a Shimadzu UV-3600 Plus spectrophotometer. Fluorescence spectra were recorded using a Shimadzu RF-5301PC spectrophotofluorimeter. The following commercially available cyclodextrin derivatives were used as received: $\alpha$-cyclodextrin, $\beta$-cyclodextrin, randomly methylated $\beta$-cyclodextrin, ${ }^{50} 2$ hydroxypropyl $\beta$-cyclodextrin, and $\gamma$-cyclodextrin. For the temperature-dependent studies, a Fisher Scientific Isotemp 6200 R20 instrument was used to control the temperature, and the spectrophotometer was equipped with a single constanttemperature cell holder. All gas chromatography-mass spectrometry (GC-MS) measurements were obtained using a Shimadzu GC-MS-QP2020 gas chromatograph-mass spectrometer. Conductivity measurements were obtained using a Thermo Scientific Orion 3-Star Benchtop Conductivity Kit. All $\mathrm{pH}$ experiments were performed using a MicroLab FS522 instrument.

Sample Collection Procedures. Water samples were collected from four locations around Rhode Island (Figure 2): Arcadia Lake, Narragansett Bay, Atlantic Ocean, and

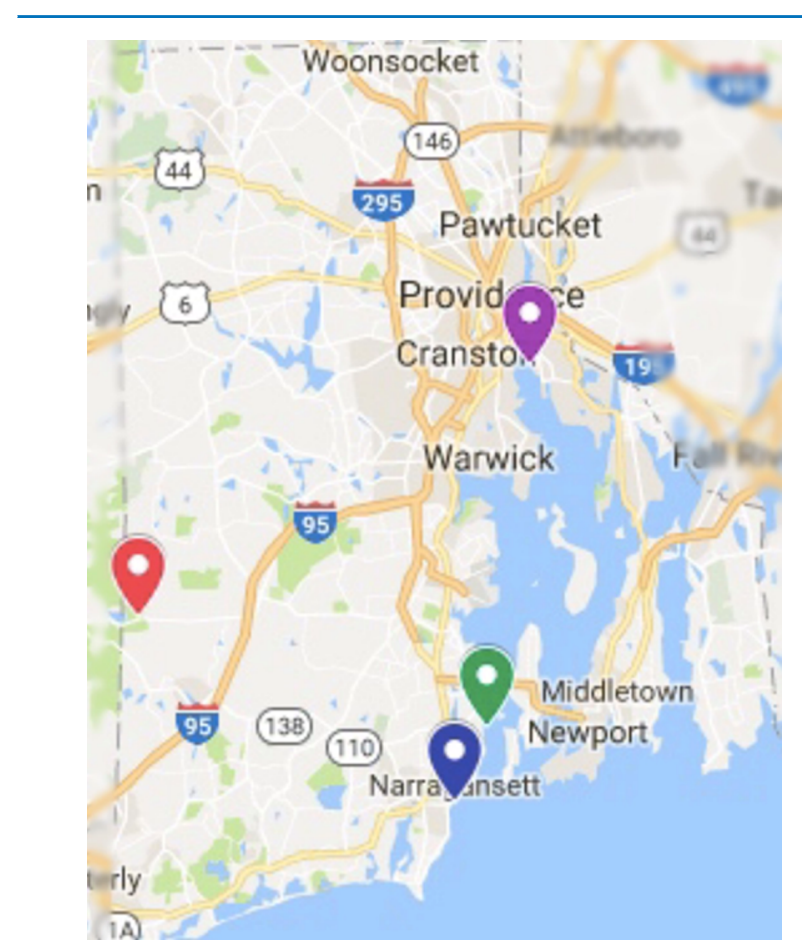

Figure 2. Map of sample collection sites. The red marker indicates Arcadia Lake, the green marker shows Narragansett Bay, the blue marker shows the Atlantic Ocean, and the purple marker shows Providence River. The map has been digitally manipulated so that only the state of Rhode Island is in focus.

Providence River. Samples were collected directly from the water using amber high-density polyethylene bottles obtained from Fisher Scientific, were transported to the University of Rhode Island in a climate-controlled vehicle within $1 \mathrm{~h}$ of collection, and were stored in the laboratory refrigerator until used for the analysis.

General Procedure for Fluorescence Modulation Experiments. In a quartz cuvette, $1.25 \mathrm{~mL}$ of a $10 \mathrm{mM}$ cyclodextrin solution dissolved in phosphate-buffered saline (PBS) and $1.25 \mathrm{~mL}$ of the water sample were combined. A fluorophore 6 solution $[100 \mu \mathrm{L}, 0.1 \mathrm{mg} / \mathrm{mL}$ in tetrahydrofuran (THF)] was added, and the solution was excited at $460 \mathrm{~nm}$. Analytes $1-4(20 \mu \mathrm{L}, 1.0 \mathrm{mg} / \mathrm{mL}$ solution in THF $)$ or control analyte $\mathbf{5}$ were added to the mixture, and the resulting solution was excited at $460 \mathrm{~nm}$. The fluorescence emission spectra were integrated versus the wavenumber on the $X$-axis, and the fluorescence modulation was measured by the ratio of integrated emission in the presence of the analyte to integrated emission of the fluorophore in the absence of the analyte, as shown in eq 1

Fluorescence modulation $=\mathrm{Fl}_{\text {analyte }} / \mathrm{Fl}_{\text {blank }}$ 
where $\mathrm{Fl}_{\text {analyte }}$ is the integrated fluorescence emission of the fluorophore in the presence of the analyte and $\mathrm{Fl}_{\text {blank }}$ is the integrated fluorescence emission of the fluorophore in the absence of the analyte. All fluorescence experiments were performed at room temperature $\left(\sim 22{ }^{\circ} \mathrm{C}\right)$.

Temperature-Dependent Fluorescence Modulation Experiments. A solution of cyclodextrin $(10 \mathrm{mM})$ was prepared in PBS. Fluorescence modulation experiments were conducted at 5 and $30^{\circ} \mathrm{C}$, as the vast majority of ocean water temperatures fall into this range. ${ }^{51,52}$ Fluorescence experiments were repeated for each water-cyclodextrin-analyte combination. The temperature control system indicated when the desired temperature was reached, and each sample was allowed to equilibrate for approximately $10 \mathrm{~min}$ at the final temperature before the fluorescence emission spectrum was collected.

General Procedure for Limit of Detection Calculations. ${ }^{53}$ The limit of detection (LOD) is defined as the lowest concentration of the analyte at which a signal can be detected. To determine this value, the following steps were performed for each water-cyclodextrin-analyte combination. In a quartz cuvette, $1.25 \mathrm{~mL}$ of $10 \mathrm{mM}$ cyclodextrin in PBS and $1.25 \mathrm{~mL}$ of water sample were combined. Then, $100 \mu \mathrm{L}$ of a $0.1 \mathrm{mg} / \mathrm{mL}$ solution of fluorophore 6 was added, the solution was excited at the excitation wavelength of fluorophore $\mathbf{6}$, and the fluorescence emission spectra were recorded. Six repeat measurements were taken.

Next, $5 \mu \mathrm{L}$ of the analyte $(1 \mathrm{mg} / \mathrm{mL}$ in THF) was doped into an aqueous sample, and again the solution was excited at the fluorophore's excitation wavelength, and the fluorescence emission spectra were recorded. Six repeat measurements were taken. This step was repeated for $10 \mu \mathrm{L}$ of the analyte, 15 $\mu \mathrm{L}$ of the analyte, $20 \mu \mathrm{L}$ of the analyte, $25 \mu \mathrm{L}$ of the analyte, 30 $\mu \mathrm{L}$ of the analyte, $35 \mu \mathrm{L}$ of the analyte, and $40 \mu \mathrm{L}$ of the analyte, all of which were doped into an aqueous sample that did not initially contain toxicants to measure the ability of the system to detect the doped toxicants within the complex aqueous matrix.

All of the fluorescence emission spectra were integrated versus wavenumber on the $X$-axis, and calibration curves were generated. The curves were plotted with the analyte concentration in micromolar on the $X$-axis and the fluorescence modulation ratio on the $Y$-axis. The curve was fitted to a straight line, and the equation of the line was determined (Figure 3).

The LOD is defined according to eq 2

$$
\mathrm{LOD}=3\left(\mathrm{SD}_{\text {blank }}\right) / m
$$

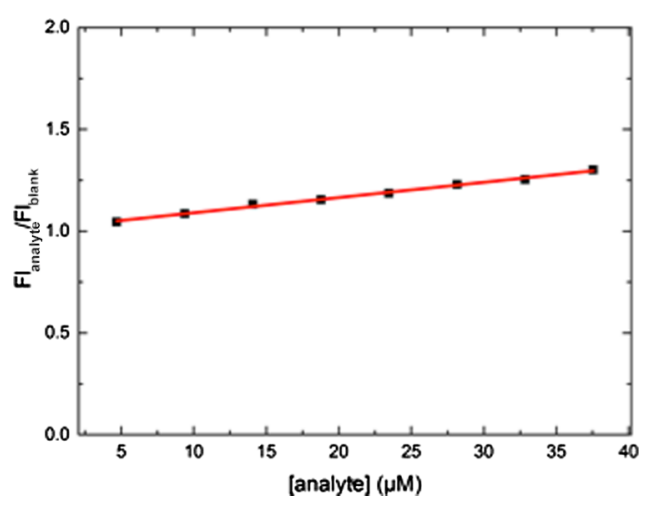

Figure 3. Example of a calibration curve used to calculate LOD. where $\mathrm{SD}_{\text {blank }}$ is the standard deviation of the blank sample and $m$ is the slope of the calibration curve. In cases where the slope of the trend line was negative, the absolute value of the slope was used to calculate the LOD. In all cases, the LOD was reported in micromolar.

General Procedure for Array Generation Experiments. Array analysis was performed using SYSTAT 13 statistical computing software with the following settings:

(a) Classical discriminant analysis.

(b) Grouping variable: analytes.

(c) Predictors: $\alpha$-cyclodextrin/BODIPY, $\beta$-cyclodextrin/ BODIPY, methyl- $\beta$-cyclodextrin/BODIPY, 2-hydroxypropyl- $\beta$-cyclodextrin/BODIPY, $\gamma$-cyclodextrin/BODIPY, and PBS/BODIPY.

(d) Long-range statistics: Mahal.

General Procedures for Water Characterization Experiments. GC-MS Experiments. The water sample $(10 \mathrm{~mL})$ and $2 \mathrm{~g}$ of sodium chloride were added to a separatory funnel. Then, $20 \mathrm{~mL}$ of dichloromethane was added to the separatory funnel, and the separatory funnel was shaken vigorously. The aqueous layer was discarded, and another $10 \mathrm{~mL}$ of water was added to the organic layer. The remaining organic layer was set to evaporate to $1 \mathrm{~mL}$ under a stream of nitrogen, filtered, and analyzed by $\mathrm{GC}-\mathrm{MS}$.

All GC-MS measurements were obtained on a ShimadzuQP2020 gas chromatograph-mass spectrometer with the following settings:

Column: Shimadzu SH-Rxi-5Sil MS $(30 \mathrm{~m} \times 0.25 \mathrm{~mm} \times$ $0.25 \mu \mathrm{m})$.

Oven temperature: $45^{\circ} \mathrm{C}$, hold for $7 \mathrm{~min}$, ramp to $200{ }^{\circ} \mathrm{C}$ at $20{ }^{\circ} \mathrm{C} / \mathrm{min}$, hold for $60 \mathrm{~min}$.

Injection temperature: $200{ }^{\circ} \mathrm{C}$.

Splitting ratio: splitless.

MS ion source temperature: $230{ }^{\circ} \mathrm{C}$.

Interface temperature: $150{ }^{\circ} \mathrm{C}$.

Total run time: $60 \mathrm{~min}$.

$\mathrm{pH}$ Experiments. All $\mathrm{pH}$ experiments were performed using a MicroLab FS-522 instrument equipped with a $\mathrm{pH}$ probe. The probe was calibrated using Fisherbrand $\mathrm{pH} \mathrm{4,} \mathrm{7,} \mathrm{and} 10$ premade buffer solutions. Data were obtained using MicroLab software version 6.3.4.

Conductivity Experiments. All conductivity experiments were performed using a Thermo Scientific Orion 3-Star Benchtop Conductivity Kit. The conductivity probe was rinsed with deionized water between samples.

\section{RESULTS AND DISCUSSION}

Water Characterization Experiments. GC-MS Experiments. Quantifiable differences between locations used for water sampling were determined via GC-MS analysis. All water samples tested showed peaks that corresponded to longchain alkanes, ${ }^{54}$ fatty acids, ${ }^{55}$ and amides ${ }^{56}$ which are commonly found in marine environments (Figure 4). Notably, Arcadia Lake showed the highest number of peaks, indicating the largest number of organic compounds, and greatest intensity of peaks, indicating the highest concentrations of each of those compounds. The higher prevalence of organic compounds in Arcadia Lake compared to the other water bodies investigated is likely due to the lack of natural cycling in lake water ${ }^{57}$ compared to the river, ocean, and bay water and the limited options for content regeneration in that lake. ${ }^{58}$ Notably, samples from Arcadia Lake also contained GC-MS 


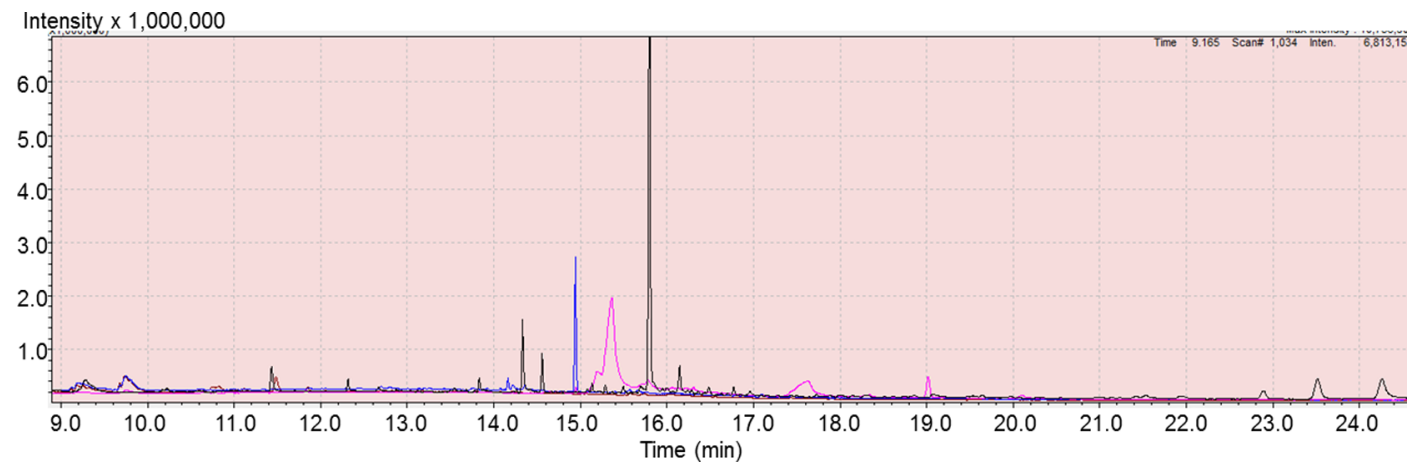

Figure 4. GC-MS overlay of water samples where the black line represents Arcadia Lake; the pink line represents Narragansett Bay; the blue line represents Atlantic Ocean; and the brown line represents Providence River.

peaks that corresponded to phthalates, commonly found in plastics $^{59}$ and other commercial products, ${ }^{60}$ and benzophenone, ${ }^{61}$ commonly used in personal care products such as sunscreen $^{62}$ and lip balm. ${ }^{63}$

$\mathrm{pH}$ and Conductivity Experiments. Differences between the four water sampling locations were further quantified through $\mathrm{pH}$ and conductivity analysis. The $\mathrm{pH}$ of water bodies can vary significantly, often becoming more acidic in locations where acid rain is prevalent ${ }^{64}$ and basic in cases where there are algal blooms $^{65}$ or other ecosystem-wide phenomena. ${ }^{66}$ The most acidic water of the four samples was the Atlantic Ocean, with a measured $\mathrm{pH}$ of 6.51 . The most basic water body was Arcadia Lake, with a $\mathrm{pH}$ of 8.28 , likely due to algal growth that is known to be highly prevalent in lake environments. The conductivity of each sample was measured and used as an indicator of salinity and electrolyte concentration, in accordance with the literature precedent. ${ }^{67,68}$ Unsurprisingly, the Atlantic Ocean sample had the highest conductivity, corresponding to the highest salt content, closely followed by the Narragansett Bay (also a saltwater location) and the Providence River. Arcadia Lake, a freshwater body, showed a markedly lower conductivity value (lowest salinity), as expected.

Fluorescence Modulation. Undoped Water Samples. In addition to measuring innate differences in water samples using $\mathrm{GC}-\mathrm{MS}, \mathrm{pH}$, and conductivity analyses, we investigated the ability of fluorophore 6 in combination with varying cyclodextrins to report on differing environments and solution compositions. To that end, analyte-free (termed "undoped") water samples were mixed with fluorophore $\mathbf{6}$ and cyclodextrins, and the fluorescence emission signals of fluorophore $\mathbf{6}$ for each sample-cyclodextrin combination were subjected to linear discriminant analysis (LDA). The results indicate 100\% success in differentiating between water samples (Figure 5), which is a result of the sensitivity of fluorophore 6cyclodextrin combinations to differences in salinity, $\mathrm{pH}$, and other sample-specific compositional variations.

Analyte-Doped Water Samples. After determining that different aqueous environments translate into different fluorescence emission responses in undoped solutions, we then evaluated the ability of fluorophore 6-cyclodextrin combinations to detect the presence of toxicants that had been doped into water, using our previously developed cyclodextrin-promoted fluorescence modulation. For each water-cyclodextrin-fluorophore 6 combination, we added small amounts of an aliphatic pesticide (compounds 1-4) as a solution in THF. We also evaluated the effect of THF itself without additional pesticide present, as control analyte 5. The

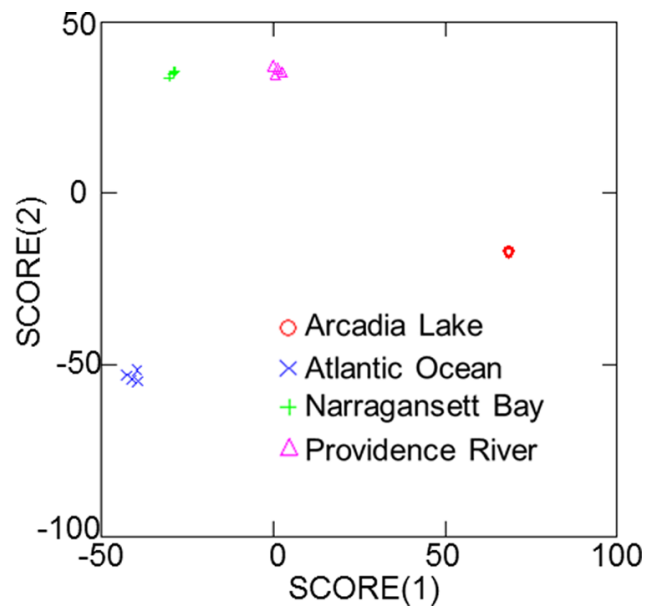

Figure 5. Array response patterns using LDA of fluorescence response signals of fluorophore 6 in water samples.

degree of modulated fluorescence emission that occurred with the introduction of analytes $1-4$ or control analyte 5 was quantified according to eq 1 . In most cases, the fluorescence modulation values were greater than 1 , indicating that introduction of the analytes led to an increase in the fluorescence emission of fluorophore 6 (Table 1).

The different cyclodextrins caused different degrees of changes in the fluorescence emission of fluorophore 6, which highlights the role of cyclodextrin as a highly specific supramolecular scaffold. Notably, the degree of fluorescence modulation for the observed analytes in the presence of $\alpha$ cyclodextrin is similar to those observed in the absence of any supramolecular host (PBS), which is likely due to the fact that $\alpha$-cyclodextrin is known to have a low affinity for the majority of organic analytes because of its highly sterically constrained cavity. ${ }^{69,70}$ Selected results from Table 1 are highlighted in Figure 6.

In addition to comparing fluorophore ratios in the presence and absence of analytes, as shown in Table 1, we can also compare the fluorescence emission intensities across different cyclodextrin hosts. As shown in Figure 5, the greatest emission intensity for fluorophore 6 was obtained in the presence of methyl- $\beta$-cyclodextrin. The high fluorescence intensity associated with methyl- $\beta$-cyclodextrin is well-known from our previous research ${ }^{43-45}$ and is likely a result of the high binding affinity of methyl- $\beta$-cyclodextrin to fluorophore 6 and related aromatic organic analytes. $^{71-73}$ 
Table 1. Selected Fluorescence Modulation Results for Analytes 1-5 in Atlantic Ocean ${ }^{a}$

\begin{tabular}{ccccccc} 
analyte & $\alpha$-CD & $\beta$-CD & Me- $\beta$-CD & 2HPCD & \multicolumn{1}{c}{ PBS } \\
1 & $1.16 \pm 0.01$ & $1.06 \pm 0.01$ & $1.03 \pm 0.01$ & $1.06 \pm 0.01$ & $1.05 \pm 0.01$ & $1.06 \pm 0.004$ \\
2 & $1.12 \pm 0.01$ & $1.05 \pm 0.01$ & $1.17 \pm 0.01$ & $1.06 \pm 0.01$ & $1.14 \pm 0.01$ \\
3 & $1.08 \pm 0.02$ & $1.04 \pm 0.004$ & $1.02 \pm 0.004$ & $1.07 \pm 0.01$ & $1.07 \pm 0.01$ \\
4 & $1.13 \pm 0.01$ & $1.05 \pm 0.004$ & $1.04 \pm 0.002$ & $1.08 \pm 0.01$ & $1.07 \pm 0.01$ \\
5 & $1.04 \pm 0.004$ & $1.04 \pm 0.005$ & $1.02 \pm 0.002$ & $1.06 \pm 0.01$ & $1.05 \pm 0.001$
\end{tabular}

${ }^{a}$ All results represent an average of the results from four trials for each sample. Fluorescence modulation values were calculated using eq 1 . Errors are shown with enough significant figures to accurately capture the errors.

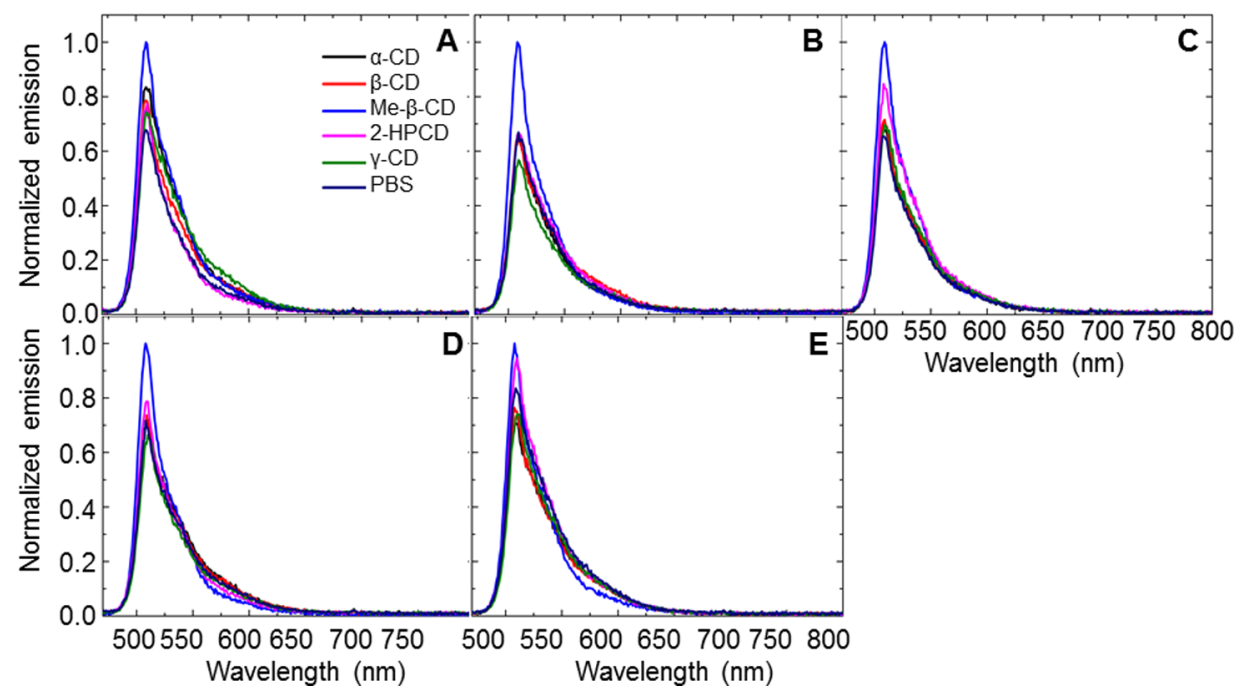

Figure 6. Fluorescence changes of fluorophore 6 upon the introduction of (A) analyte 1, (B) analyte 2, (C) analyte 3, (D) analyte 4, and (E) control analyte 5 in the Atlantic Ocean $\left(\lambda_{\mathrm{ex}}=460 \mathrm{~nm}\right)$.

Interestingly, the sampling location had an effect on the emission signals as well. The effect of sampling location on analytes $\mathbf{1}$ and $\mathbf{2}$ in the presence and absence of cyclodextrin can be seen in Figure 7. The differences between sampling locations are more pronounced and more noticeable with the methyl- $\beta$-cyclodextrin host, which highlights the advantages in using a host that promotes strong fluorescence emission signals.

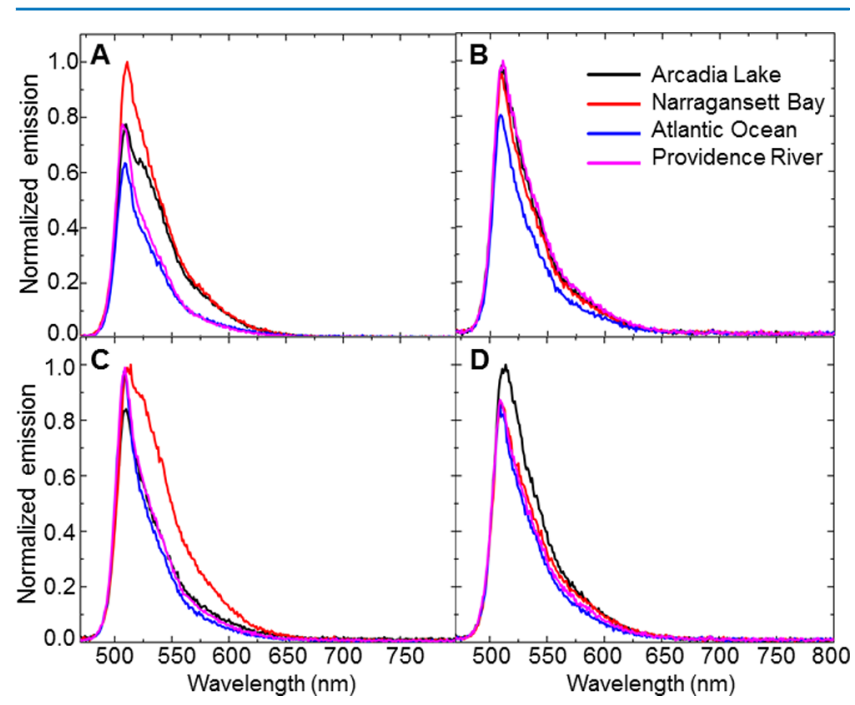

Figure 7. Fluorescence changes of fluorophore 6 in the various sampling locations in the presence of (A) analyte 1 and $\mathrm{Me}-\beta-\mathrm{CD},(\mathrm{B})$ analyte $\mathbf{1}$ and PBS, (C) analyte $\mathbf{2}$ and Me- $\beta$-CD, and (D) analyte $\mathbf{2}$ and PBS.
Differences observed between water sample locations are quantified in Table 2.

Practical Considerations. The ability to use this cyclodextrin-promoted fluorescence modulation system for the development of practical detection devices requires (a) selectivity in differentiating between structurally similar analytes, (b) sensitivity for low concentrations of pesticides, and (c) general applicability for different water samples with varying salinity and $\mathrm{pH}$, as well as for different temperatures of these water samples.

Selectivity. The selectivity of this system was determined using an array-based analysis to distinguish between structurally similar analytes. Statistical analysis of the response patterns generated from fluorescence-based detection of analytes $\mathbf{1 - 5}$ in the presence of several cyclodextrin hosts in each sampling location resulted in $100 \%$ differentiation between analytes (Figure 8).

The response patterns are markedly distinct for each water sample and show unique, well-separated signals for structurally similar organochlorine pesticides within each water sample. The high degree of success and noticeable visual differences between sampling locations highlight the power of this statistical method in distinguishing even very slight structural variations (i.e., analytes $\mathbf{1}$ and 2) and in differentiating between sampling locations. Moreover, the results indicate that the fluorescence modulation as a basis for toxicant detection operates with high selectivity in complex marine environments, regardless of the salt content (highest in the Atlantic Ocean), $\mathrm{pH}$ (varied between 6.51 and 8.28), or innate toxicant contamination levels (highest in Arcadia Lake). 
Table 2. Selected Fluorescence Modulation Results Comparing Sampling Location ${ }^{a}$

\begin{tabular}{|c|c|c|c|c|c|}
\hline analyte & cyclodextrin & Arcadia Lake & Narragansett Bay & Ocean & Providence River \\
\hline \multirow[t]{2}{*}{1} & $\mathrm{Me}-\beta-\mathrm{CD}$ & $1.17 \pm 0.01$ & $1.26 \pm 0.02$ & $1.03 \pm 0.01$ & $1.05 \pm 0.003$ \\
\hline & PBS & $1.21 \pm 0.02$ & $1.14 \pm 0.01$ & $1.15 \pm 0.01$ & $1.20 \pm 0.01$ \\
\hline \multirow[t]{2}{*}{2} & $\mathrm{Me}-\beta-\mathrm{CD}$ & $1.08 \pm 0.01$ & $1.23 \pm 0.02$ & $1.17 \pm 0.01$ & $1.05 \pm 0.01$ \\
\hline & PBS & $1.28 \pm 0.01$ & $1.14 \pm 0.01$ & $1.14 \pm 0.01$ & $1.18 \pm 0.02$ \\
\hline
\end{tabular}

${ }^{a}$ All of the results represent an average of the results from four trials for each sample. Fluorescence modulation values are calculated using eq 1 . Errors are shown with enough significant figures to accurately capture the errors.
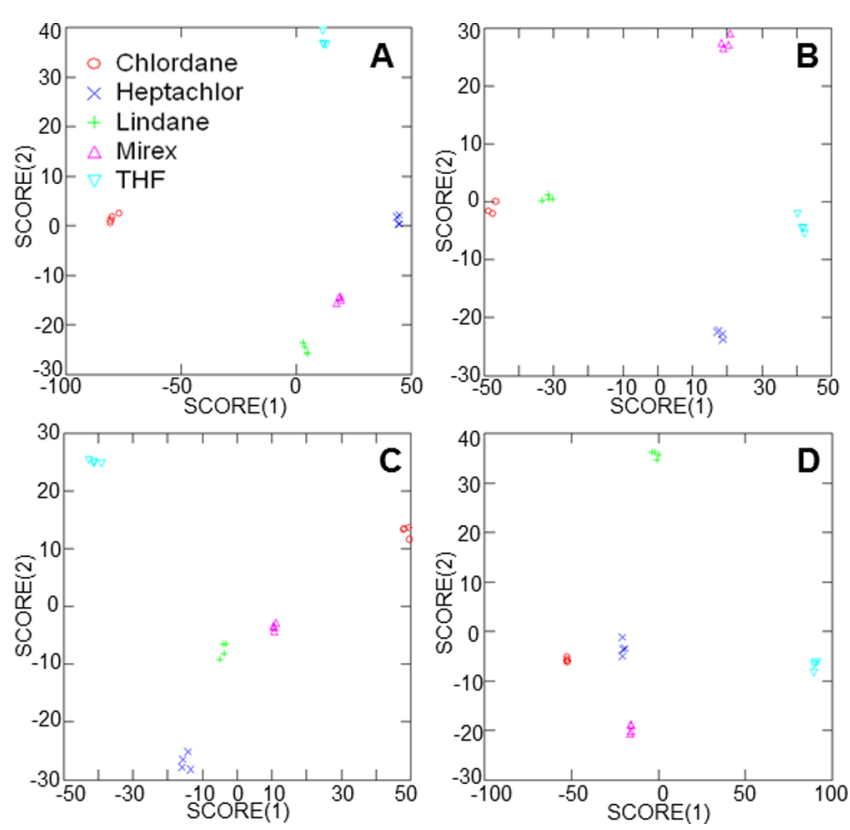

Figure 8. Array-based detection of analytes 1-5 in (A) Arcadia Lake; (B) Narragansett Bay; (C) Atlantic Ocean; and (D) Providence River.

Additionally, the array-based analysis was also performed on a sample from Arcadia Lake to see if this method could differentiate between two structurally near stereoisomeric compounds, cis-chlordane (analyte 1) and trans-chlordane (Figure 9).

The response patterns show well-separated signals for cischlordane and trans-chlordane, even in an area of high innate toxicant contamination levels as in Arcadia Lake. This

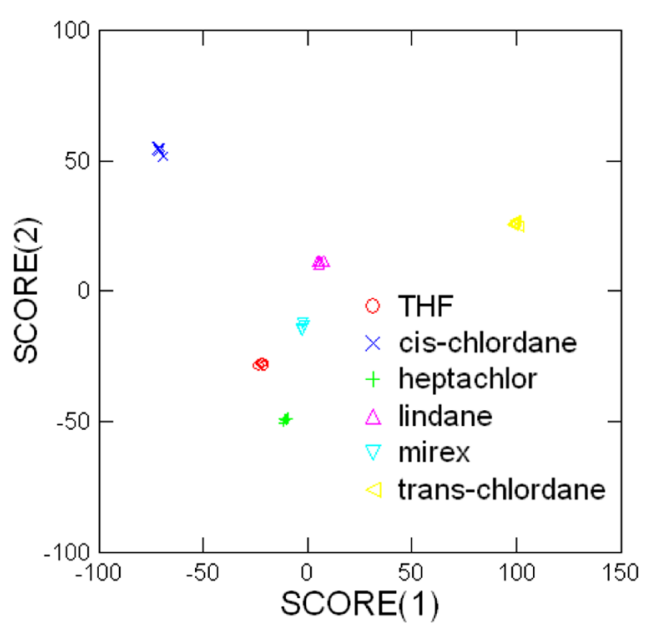

Figure 9. Array-based detection of analytes 1-5 and trans-chlordane Arcadia Lake. highlights the power of this method to distinguish between cis and trans isomers, which is a difficult task even for highly specialized and costly instrumentation.

Sensitivity. The sensitivity of this system was determined by calculating LODs for all water-methyl- $\beta$-cyclodextrin-analyte combinations following literature-reported procedures, and the results of these studies are summarized in Table 3.

\section{Table 3. LODs for Analytes 1-4 in Water Samples ${ }^{a}$}

\begin{tabular}{cll} 
analyte & sampling location & LOD $(\mathrm{ppm})$ \\
\hline $\mathbf{1}$ & Arcadia Lake & $1.71 \pm 0.02$ \\
& Narragansett Bay & $0.50 \pm 0.002$ \\
Atlantic Ocean & $0.41 \pm 0.001$ \\
Providence River & $2.67 \pm 0.01$ \\
& Arcadia Lake & $4.25 \pm 0.08$ \\
Narragansett Bay & $0.81 \pm 0.01$ \\
& Atlantic Ocean & $0.21 \pm 0.001$ \\
\multirow{2}{*}{3} & Providence River & $0.55 \pm 0.002$ \\
& Arcadia Lake & $3.08 \pm 0.01$ \\
& Narragansett Bay & $0.50 \pm 0.001$ \\
& Atlantic Ocean & $0.28 \pm 0.002$ \\
& Providence River & $0.63 \pm 0.002$ \\
Arcadia Lake & $2.19 \pm 0.02$ \\
& Narragansett Bay & $5.56 \pm 0.03$ \\
& Atlantic Ocean & $1.07 \pm 0.01$ \\
& Providence River & $1.94 \pm 0.004$
\end{tabular}

${ }^{a}$ LODs were calculated using the procedures in Cheng 2016; see the Supporting Information for more information. Errors are shown with enough significant figures to accurately capture the errors.

These detection limits are near or below the $0.5 \mathrm{ppm}$ literature-reported levels of concern in many cases. ${ }^{74-76}$ In general, the LODs for analytes in Arcadia Lake were slightly higher than those measured in the other aqueous environments. This is likely due to the higher innate levels of toxicants found in this lake that can interfere with favorable intermolecular interactions and are slightly lower than the system sensitivity under those conditions. Current efforts in our laboratory are focused on lowering the detection limits for cases where the detection limits are above the literature-reported levels of concern using other fluorophores and/or cyclodextrin hosts. We are also exploring the use of a preconcentration step in conjunction with this system to achieve higher effective concentrations of the toxicant analytes. ${ }^{77-79}$

General Applicability. The general applicability of this system was determined using cyclodextrin-promoted fluorescence modulation and subsequent array-based analyses at varying temperatures, focused particularly on seasonal temperature variations of the Rhode Island water to include extreme winter temperatures $\left(5^{\circ} \mathrm{C}\right)$ and extreme summer temperatures $\left(30{ }^{\circ} \mathrm{C}\right)$. Detection at these temperatures resulted in $100 \%$ success in differentiating and identifying the pesticide analytes, 
which highlights the ability of this detection system to operate at a broad variety of temperatures, including most measured ocean temperatures (Figure 10). ${ }^{80,81}$ This selectivity was
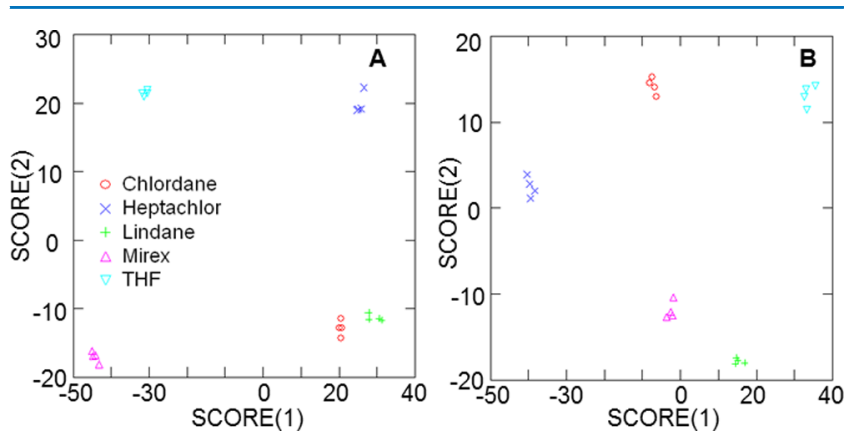

Figure 10. Array-based detection of analytes 1-5 in Arcadia Lake at (A) 5 and (B) $30{ }^{\circ} \mathrm{C}$.

applied even in real-world complicated environments, which contained some amount of innate organic matter, as measured by GC-MS (vide supra) and supported by the literature precedent. $^{82}$

Additionally, the general applicability was also highlighted by comparing the fluorescence response signals of a single-target analyte in four different water samples, all of which have differences in their chemical compositions (see GC-MS Experiments section above). For these experiments, we selected analyte 1, and the integrated fluorescence responses from fluorophore $\mathbf{6}$ in the presence of analyte $\mathbf{1}$ in four different water samples yielded four unique response signals (Figure 11).

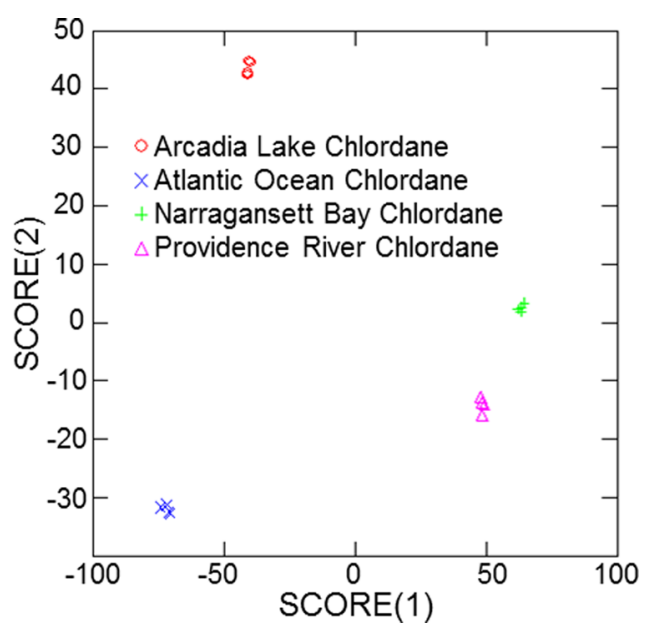

Figure 11. Array response patterns using LDA of response patterns of analyte $\mathbf{1}$ in all water sampling locations.

Statistical analysis of these results provided $100 \%$ success in identifying the water sampling location in which the analyte was found. The well-separated, distinct signals for each water sample highlight the potential for profiling sampling locations based on such identification and creating water sampling location-specific patterns for accurate identification purposes.

\section{CONCLUSIONS}

In summary, cyclodextrin-promoted fluorescence modulation can be used for the detection of organochlorine pesticides in contaminated marine environments. This method is selective (100\% successful in differentiating structurally similar analytes such as cis-chlordane and trans-chlordane), sensitive (sub-ppm detection limits, with slightly higher limits observed in Arcadia Lake for some analytes), and generally applicable (for different water samples with varying salinity, including freshwater and saltwater, and $\mathrm{pH}$ as well as for different temperatures of these water samples including most measured temperatures of ocean water). The high selectivity, sensitivity, and general applicability show the potential for the development of practically applicable portable detection devices. Future work in our laboratory will be dedicated toward lowering the detection limits to achieve optimal sensitivity and further developing this method into a portable detection device for the detection of pesticides in contaminated marine environments.

\section{ASSOCIATED CONTENT}

\section{Supporting Information}

The Supporting Information is available free of charge on the ACS Publications website at DOI: 10.1021/acsomega.7b00991.

Synthesis of fluorophore 6; details of fluorescence modulation, LOD, and characterization experiments; summary tables and summary figures for all experiments (PDF)

\section{AUTHOR INFORMATION}

\section{Corresponding Author}

*E-mail: mindy.levine@gmail.com. Phone: 401-874-4243 (M.L.).

\section{ORCID}

Mindy Levine: 0000-0003-4847-7791

\section{Notes}

The authors declare no competing financial interest.

\section{ACKNOWLEDGMENTS}

Funding is acknowledged from the Rhode Island-National Science Foundation (RI-NSF) and the Experimental Program to Stimulate Competitive Research (EPSCoR).

\section{REFERENCES}

(1) Betianu, C.; Gavrilescu, M. Persistent organic pollutants in environment: inventory procedures and management in the context of the Stockholm convention. Environ. Eng. Manage. J. 2006, 5, 10111028.

(2) Alikhanidi, S.; Takahashi, Y. Pesticide persistence in the environment-collected data and structure-based analysis. J. Comput. Chem., Jpn. 2004, 3, 59-70.

(3) Fenner, K.; Scheringer, M.; Hungerbühler, K. Prediction of overall persistence and long-range transport potential with multimedia fate models: robustness and sensitivity of results. Environ. Pollut. 2004, 128, 189-204.

(4) Král'ová, K.; Jampílek, J. Impact of environmental contaminants on breast cancer. Ecol. Chem. Eng. S 2015, 22, 9-44.

(5) Ljunggren, S. A.; Helmfrid, I.; Salihovic, S.; van Bavel, B.; Wingren, G.; Lindahl, M.; Karlsson, H. Persistent organic pollutants distribution in lipoprotein fractions in relation to cardiovascular disease and cancer. Environ. Int. 2014, 65, 93-99.

(6) Gangemi, S.; Miozzi, E.; Teodoro, M.; Briguglio, G.; De Luca, A.; Alibrando, C.; Polito, I.; Libra, M. Occupational exposure to pesticides as a possible risk factor for the development of chronic diseases in humans. Mol. Med. Rep. 2016, 14, 4475-4488.

(7) Singh, Z.; Kaur, J.; Kaur, R.; Hundal, S. S. Toxic effects of organochlorine pesticides: a review. Am. J. BioSci. 2016, 4, 11-18.

(8) Brunetto, G.; Bastos de Melo, G. W.; Terzano, R.; Del Buono, D.; Astolfi, S.; Tomasi, N.; Pii, Y.; Mimmo, T.; Cesco, S. Copper 
accumulation in vineyard soils: Rhizosphere processes and agronomic practices to limit its toxicity. Chemosphere 2016, 162, 293-307.

(9) Douglas, M. R.; Tooker, J. F. Large-scale deployment of seed treatments has driven rapid increase in use of neonicotinoid insecticides and preemptive pest management in U.S. field crops. Environ. Sci. Technol. 2015, 49, 5088-5097.

(10) Liu, Y.; Pan, X.; Li, J. A 1961-2010 record of fertilizer use, pesticide application and cereal yields: a review. Agron. Sustainable Dev. 2015, 35, 83-93.

(11) Servin, A.; Elmer, W.; Mukherjee, A.; De la Torre-Roche, R; Hamdi, H.; White, J. C.; Bindraban, P.; Dimkpa, C. A review of the use of engineered nanomaterials to suppress plant disease and enhance crop yield. J. Nanopart. Res. 2015, 17, 92.

(12) Igboji, P. O. Pesticides in crop management: environmental implications and future challenges (a review). Elixir Int. J. 2016, 38156-38163.

(13) Deyerling, D.; Wang, J.; Bi, Y.; Peng, C.; Pfister, G.; Henkelmann, B.; Schramm, K.-W. Depth profile of persistent and emerging organic pollutants upstream of the Three Gorges Dam gathered in 2012/2013. Environ. Sci. Pollut. Res. 2016, 23, 5782-5794.

(14) Santolaria, Z.; Arruebo, T.; Pardo, A.; Matesanz, J. M.; Bartolomé, A.; Caixach, J.; Lanaja, F. J.; Urieta, J. S. Evaluation of airborne organic pollutants in a Pyrenean glacial lake (The Sabocos Tarn). Water, Air, Soil Pollut. 2015, 226, 383.

(15) Jacob, S.; Resmi, G. Study and prediction of persistent organochlorine and organophosphorous pesticide residue in soils of cardamom plantations in Idukki district (India). IOSR J. Environ. Sci., Toxicol. Food Technol. 2015, 9, 01-07.

(16) Kilunga, P. I.; Sivalingam, P.; Laffite, A.; Grandjean, D.; Mulaji, C. K.; de Alencastro, L. F.; Mpiana, P. T.; Poté, J. Accumulation of toxic metals and organic micro-pollutants in sediments from tropical urban rivers, Kinshasa, Democratic Republic of the Congo. Chemosphere 2017, 179, 37-48.

(17) Misra, K.; Brar, K. S.; Verma, M.; Tyagi, R. D.; Trivedy, R. K.; Sharma, S. Lindane-a contaminant of global concern. J. Ind. Pollut. Control 2007, 23, 169-187.

(18) Patil, S. G.; Deshpande, P. B.; Awasthi, M. D. Persistence of dimethoate in saline environment. Indian J. Agric. Chem. 1987, 20, 223-229.

(19) Jackson, R. E.; Mutch, J. P.; Priddle, M. W. Persistence of Aldicarb residues in the sandstone aquifer of Prince Edward Island, Canada. J. Contam. Hydrol. 1990, 6, 21-35.

(20) Vighi, M.; Matthies, M.; Solomon, K. R. Critical assessment of pendimethalin in terms of persistence, bioaccumulation, toxicity, and potential for long-range transport. J. Toxicol. Environ. Health, Part B 2017, 20, 1-21.

(21) Mrema, E. J.; Rubino, F. M.; Brambilla, G.; Moretto, A.; Tsatsakis, A. M.; Colosio, C. Persistent organochlorinated pesticides and mechanisms of their toxicity. Toxicology 2013, 307, 74-88.

(22) Mearns, A. J.; Reish, D. J.; Oshida, P. S.; Ginn, T.; RempelHester, M. A.; Arthur, C.; Rutherford, N.; Pryor, R. Effects of pollution on marine organisms. Water Environ. Res. 2015, 87, 1718-1816.

(23) Berenbaum, M. R. Does the honey bee "risk cup" runneth over? Estimating aggregate exposures for assessing pesticide risks to honey bees in agroecosystems. J Agricultur. Food Chem. 2016, 64, 13-20.

(24) Fernandes, V. C.; Domingues, V. F.; Mateus, N.; DelerueMatos, C. Organochlorine pesticide residues in strawberries from integrated pest management and organic farming. J. Agric. Food Chem. 2011, 59, 7582-7591.

(25) Tomer, V.; Sangha, J. K.; Ramya, H. G. Pesticide: an appraisal on human health Implications. Proc. Natl. Acad. Sci., India, Sect. B 2015, 85, 451-463.

(26) Ewence, A.; Brescia, S.; Johnson, I.; Rumsby, P. C. An approach to the identification and regulation of endocrine disrupting pesticides. Food Chem. Toxicol. 2015, 78, 214-220.

(27) Coles, T. B.; Dryden, M. W. Insecticide/acaricide resistance in fleas and ticks infesting dogs and cats. Parasites Vectors 2014, 7, 8-17.

(28) Zhao, R. Recent developments in gas chromatography-mass spectrometry for the detection of food chemical hazards. In Food
Chemical Hazard Detection: Development and Application of New Technologies; Wang, S., Ed.; John Wiley \& Sons, Ltd: Chichester, U.K., 2014; pp 3-52.

(29) Corcellas, C.; Eljarrat, E.; Barceló, D. Determination of pyrethroid insecticides in environmental samples by GC-MS and GC-MS-MS. Comprehensive Analytical Chemistry; Elsevier B.V., 2013; Vol. 61, pp 203-230.

(30) Wong, J. W.; Hayward, D. G.; Zhang, K. Gas chromatographymass spectrometry techniques for multiresidue pesticide analysis in agricultural commodities. Comprehensive Analytical Chemistry; Elsevier B.V., 2013; Vol. 61, pp 3-22.

(31) Saute, B.; Narayanan, R. Solution-based SERS method to detect dithiocarbamate fungicides in different real-world matrices. J. Raman Spectrosc. 2013, 44, 1518-1522.

(32) Saute, B.; Premasiri, R.; Ziegler, L.; Narayanan, R. Gold nanorods as surface enhanced Raman spectroscopy substrates for sensitive and selective detection of ultra-low levels of dithiocarbamate pesticides. Analyst 2012, 137, 5082-5087.

(33) Guo, Y.; Gong, Z.; Cao, Y.; Wang, X.; Sun, X. Electrochemical immunosensor for pesticide residues detection in food analysis. Sens. Transducers J. 2013, 156, 374-378.

(34) Mako, T.; Marks, P.; Cook, N.; Levine, M. Fluorescent detection of polycyclic aromatic hydrocarbons in ternary cyclodextrin complexes. Supramol. Chem. 2012, 24, 743-747.

(35) Serio, N.; Miller, K.; Levine, M. Efficient detection of polycyclic aromatic hydrocarbons and polychlorinated biphenyls via threecomponent energy transfer. Chem. Commun. 2013, 49, 4821-4823.

(36) Serio, N.; Prignano, L.; Peters, S.; Levine, M. Detection of medium-sized polycyclic aromatic hydrocarbons via fluorescence energy transfer. Polycyclic Aromat. Compd. 2014, 34, 561-572.

(37) Serio, N.; Moyano, D. F.; Rotello, V. M.; Levine, M. Array-based detection of persistent organic pollutants via cyclodextrin promoted energy transfer. Chem. Commun. 2015, 51, 11615-11618.

(38) Serio, N.; Roque, J.; Badwal, A.; Levine, M. Rapid and efficient pesticide detection via cyclodextrin-promoted energy transfer. Analyst 2015, 140, 7503-7507.

(39) DiScenza, D. J.; Gareau, L.; Serio, N.; Roque, J.; Prignano, L.; Verderame, M.; Levine, M. Cyclodextrin-promoted detection of aromatic toxicants and toxicant metabolites in urine. Anal. Chem. Lett. 2016, 6, 345-353.

(40) DiScenza, D. J.; Lynch, J.; Verderame, M.; Serio, N.; Prignano, L.; Gareau, L.; Levine, M. Efficient fluorescence detection of aromatic toxicants and toxicant metabolites in human breast milk. Supramol. Chem. 2017, 0, 1-11.

(41) Serio, N.; Chanthalyma, C.; Prignano, L.; Levine, M. Cyclodextrin-enhanced extraction and energy transfer of carcinogens in complex oil environments. ACS Appl. Mater. Interfaces 2013, 5, 11951-11957.

(42) Serio, N.; Chanthalyma, C.; Peters, S.; Levine, D.; Levine, M. 2Hydroxypropyl beta-cyclodextrin for the enhanced performance of dual function extraction and detection systems in complex oil environments. J. Inclusion Phenom. Macrocyclic Chem. 2015, 81, 341346.

(43) Serio, N.; Levine, M. Efficient extraction and detection of aromatic toxicants from crude oil and tar balls using multiple cyclodextrin derivatives. Mar. Pollut. Bull. 2015, 95, 242-247.

(44) Serio, N.; Levine, M. Solvent effects in the extraction and detection of polycyclic aromatic hydrocarbons from complex oils in complex environments. J. Inclusion Phenom. Macrocyclic Chem. 2016, $84,61-70$.

(45) Serio, N.; Chanthalyma, C.; Prignano, L.; Levine, M. Cyclodextrin-promoted energy transfer for broadly applicable smallmolecule detection. Supramol. Chem. 2014, 26, 714-721.

(46) DiScenza, D. J.; Verderame, M.; Levine, M. Detection of benzene and alkylated benzene derivatives in fuel contaminated environments. Clean: Soil, Air, Water 2016, 44, 1621-1627.

(47) DiScenza, D. J.; Levine, M. Sensitive and selective detection of alcohols via fluorescence modulation. Supramol. Chem. 2016, 28, 881891. 
(48) DiScenza, D. J.; Levine, M. Selective detection of non-aromatic pesticides via cyclodextrin-promoted fluorescence modulation. New J. Chem. 2016, 40, 789-793.

(49) Shepherd, J. L.; Kell, A.; Chung, E.; Sinclar, C. W.; Workentin, M. S.; Bizzotto, D. Selective reductive desorption of a SAM-coated gold electrode revealed using fluorescence microscopy. J. Am. Chem. Soc. 2004, 126, 8329-8335.

(50) Storsberg, J.; Ritter, H. Cyclodextrins in polymer synthesis: free radical polymerization of cyclodextrin host-guest complexes of methyl methacrylate or styrene from homogenous aqueous solution. Macromol. Rapid Commun. 2000, 21, 236-241.

(51) Oren, A. Limnological instrumentation in the middle of the 19th century: the first temperature and density profiles measured in the Dead Sea. Chin. J. Oceanol. Limnol. 2015, 33, 1496-1504.

(52) Faizal, M.; Ahmed, M. R. On the ocean heat budget and ocean thermal energy conversion. Int. J. Energy Res. 2011, 35, 1119-1144.

(53) Cheng, D.; Zhao, W.; Yang, H.; Huang, Z.; Liu, X.; Han, A. Detection of $\mathrm{Hg} 2+$ by a FRET ratiometric fluorescent probe based on a novel BODIPY-RhB system. Tetrahedron Lett. 2016, 57, 2655-2659. (54) He, D.; Simoneit, B. R. T.; Jara, B.; Jaffé, R. Compositions and isotopic differences of iso- and anteiso-alkanes in black mangroves (Avicennia germinans) across a salinity gradient in a subtropical estuary. Environ. Chem. 2016, 13, 623-630.

(55) Longnecker, K.; Kujawinski, E. B. Mining mass spectrometry data: Using new computational tools to find novel organic compounds in complex environmental mixtures. Org. Geochem. 2017, 110, 92-99.

(56) Rayne, S.; Forest, K. Modeling the hydrolysis of perfluorinated compounds containing carboxylic and phosphoric acid ester functions and sulfonamide groups. J. Environ. Sci. Health, Part A: Toxic/Hazard. Subst. Environ. Eng. 2010, 45, 432-446.

(57) Molinos, J. G.; Viana, M.; Brennan, M.; Donohue, I. Importance of long-term cycles for predicting water level dynamics in natural lakes. PLoS One 2015, 10, No. e0119253.

(58) Xie, D.; Zhou, H.; Zhu, H.; Ji, H.; Li, N.; An, S. Differences in the regeneration traits of Potamogeton crispus turions from macrophyte- and phytoplankton-dominated lakes. Sci. Rep. 2015, 5, 12907.

(59) Yuzawa, T.; Watanabe, C.; Freeman, R. R.; Tsuge, S. Rapid and simple determination of phthalates in plastic toys by a thermal desorption-GC/MS method. Anal. Sci. 2009, 25, 1057-1058.

(60) Staples, C. A.; Guinn, R.; Kramarz, K.; Lampi, M. Assessing the chronic aquatic toxicity of phthalate ester plasticizers. Hum. Ecol. Risk Assess. 2011, 17, 1057-1076.

(61) Zhang, F.; Zhang, J.; Tong, C.; Chen, Y.; Zhuang, S.; Liu, W. Molecular interactions of benzophenone UV filters with human serum albumin revealed by spectroscopic techniques and molecular modeling. J. Hazard. Mater. 2013, 263, 618-626.

(62) Ruszkiewicz, J. A.; Pinkas, A.; Ferrer, B.; Peres, T. V.; Tsatsakis, A.; Aschner, M. Neurotoxic effect of active ingredients in sunscreen products, a contemporary review. Toxicol. Rep. 2017, 4, 245-259.

(63) Schram, S. E.; Glesne, L. A.; Warshaw, E. M. Allergic contact cheilitis from benzophenone-3 in lip balm and fragrance/flavorings. Dermatitis 2007, 18, 221-224.

(64) Yu, T.; Xu, Q.; He, C.; Cong, H.; Dai, D.; Wu, F.; Meng, W. Long-term trends in acid neutralizing capacity under increasing acidic deposition: A special example of eutrophic Taihu Lake, China. Environ. Sci. Technol. 2016, 50, 12660-12668.

(65) Yilmaz, E.; Koc, C. Research on water quality of Lake Bafa in Turkey. Environ. Eng. Manage. J. 2014, 13, 153-162.

(66) Randall, D. J.; Wright, P. A. The interaction between carbon dioxide and ammonia excretion and water $\mathrm{pH}$ in fish. Can. J. Zool. 1989, 67, 2936-2942.

(67) Bosker, T.; Santoro, G.; Melvin, S. D. Salinity and sensitivity to endocrine disrupting chemicals: A comparison of reproductive endpoints in small-bodied fish exposed under different salinities. Chemosphere 2017, 183, 186-196.

(68) Ukpai, S. N.; Okogbue, C. O. Geophysical, geochemical and hydrological analyses of water-resource vulnerability to salinization: case of the Uburu-Okposi salt lakes and environs, southeast Nigeria. Hydrogeol. J. 2017, 25, 1997-2014.

(69) Linden, L.; Goss, K.-U.; Endo, S. 3D-QSAR predictions for $\alpha$ cyclodextrin binding constants using quantum mechanically based descriptors. Chemosphere 2017, 169, 693-699.

(70) Pursell, J. L.; Pursell, C. J. Host-guest inclusion complexation of $\alpha$-cyclodextrin and triiodide examined using UV-Vis spectrophotometry. J. Phys. Chem. A 2016, 120, 2144-2149.

(71) Greene, L.; Elzey, B.; Franklin, M.; Fakayode, S. O. Analyses of polycyclic aromatic hydrocarbon (PAH) and chiral-PAH analoguesmethyl- $\beta$-cyclodextrin guest-host inclusion complexes by fluorescence spectrophotometry and multivariate regression analysis. Spectrochim. Acta, Part A 2017, 174, 316-325.

(72) Sangpheak, W.; Kicuntod, J.; Schuster, R.; Rungrotmongkol, T.; Wolschann, P.; Kungwan, N.; Viernstein, H.; Mueller, M.; Pongsawasdi, P. Physical properties and biological activities of hesperetin and naringenin in complex with methylated $\beta$-cyclodextrin. Beilstein J. Org. Chem. 2015, 11, 2763-2773.

(73) Das, R.; Duportail, G.; Ghose, A.; Richert, L.; Klymchenko, A.; Chakraborty, S.; Yesylevskyy, S.; Mely, Y. Tuning excited-state proton transfer dynamics of a 3-hydroxychromone dye in supramolecular complexes via host-guest steric compatibility. Phys. Chem. Chem. Phys. 2014, 16, 776-784.

(74) Occupational Safety \& Health Administration (2012). Chemical Sampling Information: Chlordane. https://www.osha.gov/dts/ chemicalsampling/data/CH 226200.html (accessed July 13, 2017).

(75) Occupational Safety \& Health Administration (2012). Chemical Sampling Information: Lindane. https://www.osha.gov/dts/ chemicalsampling/data/CH_249500.html (accessed July 13, 2017).

(76) Occupational Safety \& Health Administration (2012). Chemical Sampling Information: Mirex. https://www.osha.gov/dts/ chemicalsampling/data/CH_255060.html (accessed July 13, 2017).

(77) Hu, M.; Huang, P.; Suo, L.; Wu, F. Cetylpyridinium chloride functionalized silica-coated magnetite microspheres for the solid-phase extraction and pre-concentration of ochratoxin A from environmental water samples with high-performance liquid chromatographic analysis. J. Sep. Sci. 2017, 40, 2431-2437.

(78) Hogard, M. L.; Lunte, C. E.; Lunte, S. M. Detection of reactive aldehyde biomarkers in biological samples using solid-phase extraction pre-concentration and liquid chromatography with fluorescence detection. Anal. Methods 2017, 9, 1848-1854.

(79) Aufartová, J.; Brabcová, I.; Torres-Padrón, M. E.; Solich, P.; Sosa-Ferrera, Z.; Santana-Rodríguez, J. J. Determination of fluoroquinolones in fishes using microwave-assisted extraction combined with ultra-high performance liquid chromatography and fluorescence detection. J. Food Compos. Anal. 2017, 56, 140-146.

(80) Lentz, S. J.; Shearman, R. K.; Plueddemann, A. J. Heat and salt balances over the New England continental shelf, August 1996 to June 1997. J. Geophys. Res.: Oceans 2010, 115, C07017.

(81) Savage, K. E.; Davidson, E. A. Interannual variation of soil respiration in two New England forests. Global Biogeochem. Cycles 2001, 15, 337-350.

(82) Mostofa, K. M. G.; Wu, F.; Liu, C.-Q.; Vione, D.; Yoshioka, T.; Sakugawa, H.; Tanoue, E. Photochemical, microbial and metal complexation behavior of fluorescent dissolved organic matter in the aquatic environments. Geochem. J. 2011, 45, 235-254. 